\title{
Structural Behavior of Resilient Materials Subjected to Short-Term Load and Long-Term Load
}

\author{
Jung-Yoon Lee, Su-Chan Lee, Seong-Ho Choi, Ah-Ra Lim, Ji-Sun Park, and Jong-Mun Kim
}

\begin{abstract}
The number of high-rise apartment houses has been steadily increasing since the 1980's in a densely populated country. More than 58 percent of Koreans are living in apartment houses in 2012. One of the big residential environment concerns in living apartment houses is noise pollution induced by floor impact sound. Korean government regulates light-weigh impact sound and heavy-weigh impact sound to be lower than $58 \mathrm{~dB}$ and $50 \mathrm{~dB}$, respectively. To reduce floor impact sound, resilient materials are commonly used. The most common types of resilient material available in Korea are Ethylene Polystyrene(EPS) and Ethylene Vinyl Acetate(EVA) made from rubber. The flexible EPS is known for being soft, and it also possess a natural springiness, especially when installed over a sprung reinforced concrete slabs. These resilient materials placing between reinforced concrete slab and finishing mortar should not only reduce floor impact sound vibrated from the floor but also support load on the floor. This paper presents the test results of the structural behavior of sound reduction materials. Twenty-four sound reduction materials were tested. The main parameters of test were magnitude of load and duration of load. Test results indicated that the duration of load strongly effects on the structural behavior of resilient materials for reduction of floor impact sound.
\end{abstract}

\section{INTRODUCTION}

Resilient materials placing between slab and finishing material offer a simple but effective solution to reduce floor impact sound in multiple-story dwellings, condominiums, hotels, and apartments. There are various types of resilient materials used in reinforced concrete apartment buildings in order to reduce floor impact sound. The most common types of resilient materials available in Korea are Ethylene Polystyrene (EPS) and Ethylene Vinyl Acetate (EVA) made from rubber. The flexible EPS is known for being soft, and it

Manuscript received April 15, 2013; revised July 10, 2013. This research was supported by a grant (13CTAP-C066421-01) from Construction \& Transportation Technology Advancement Research Program funded by Ministry of Land, Transport and Maritime Affairs of Korean government.

Jung-Yoon Lee is with Department of Civil and Architectural Engineering, Sungkyunkwan University, 440-746, Jang-an Gu, Suwon, Republic of Korea (e-mail: jungyoon@ skku.edu).

Su-Chan Lee, Seong-Ho Choi, and Ah-Ra Lim are with Department of Mega Buildings and Bridges, Sungkyunkwan University, 440-746, Jang-an $\mathrm{Gu}$, Suwon, Republic of Korea (e-mail: leesuchan@naver.com, gmfmsmsekf@naver.com, e-mail: ararra@hotmail.com).

Ji-Sun Park is with Advanced Building Research Division, Building Research Department, Korea Institute of Construction Technology, 283 Goyangdae-Ro, Ilsanseo-Gu, Goyang-Si, Gyeonggi-Do, 411-712, Republic of Korea (e-mail: batsun@kict.re.kr).

Jong-Mun Kim is with Department of Global Construction Engineering, Sungkyunkwan University, 440-746, Jang-an Gu, Suwon, Republic of Korea (e-mail: kjmgodzz@naver.com). also possesses a natural springiness, especially when installed over a sprung reinforced concrete slabs. These resilient materials placing between reinforced concrete slab and finishing mortar should not only reduce floor impact sound vibrated from the floor but also support load on the floor.

It is generally accepted that floor impact sound reduction increases as the dynamic stiffness of resilient material decreases. In order to decrease the dynamic stiffness of material, the density of material should be reduced. Therefore there is some possibility that low density resilient materials cannot resist the load on the floor. As a result, cracks develop on the finishing mortar and the floor sags.

In order to investigate the dynamic stiffness of resilient material, Kim et al. [1] tested several types of resilient materials, such as EPS, recycled urethane types, EVA, foam $\mathrm{PE}$ (Polyethylene), glass fiber and rock wool, recycled tire, foam polypropylene, compressed polyester, and other synthetic materials. Test results indicated that the amount of heavy-weight impact sound reduced as the dynamic stiffness of resilient material decreased. Im et al. [2] tested several multi-layered damping materials used to improve the effect of floor impact noise insulation. Test results indicated that the dynamic stiffness of multi-layered damping material consisting of expanded polystyrene (EPS), expended polyethylene (EPE), ethylene vinyl acetate (EVA) and polyester could be estimated by using the material proprieties of components. And it was also found that the dynamic stiffness of whole structure did not change even if the disposition of components changed. In addition, Kim et al. [3] indicated that the floor impact sound reduction level tended to increase as the frequency increased, and the reduction level clearly varied depending on the differences in dynamic stiffness. As the dynamic stiffness decreased, the resonance frequency decreased and the impact sound reduction level increased. There are several methods to measure the structural behavior of resilient materials for reducing floor impact sound. Din En 12431[4] and ISO 20392[5] determine the deflection capacity or creep of insulation materials based on the test results of the materials subjected to relatively short-term load. However, because the resilient materials for reducing floor impact sound has small elastic area in its stress vs. strain curve, there is possibility that the structural behavior of resilient materials subjected to short-term load is different to that of materials subjected to long-term load. Therefore, the structural behavior of sound reduction materials subjected to different loading periods was investigated in this study.

\section{MATERIALS}

Two types of materials for reducing floor impact sound 
were tested; Ethylene Polystyrene (EPS) and Ethylene Vinyl Acetate (EVA). The EPS materials were subdivided into three types according to density $\left(25 \mathrm{kgf} / \mathrm{m}^{3}\right.$ and $\left.13 \mathrm{kgf} / \mathrm{m}^{3}\right)$ and bottom shapes (plat shape and corrugated shape, see Fig. 1). The EVA materials were subdivided into two types according to bottom shape (plat shape and embossed shape). Figs. 1 (a) and (b) represented the plate and corrugated shape EPS specimens, respectively, whereas Figs. 1(c) and (d) represent the plat and embossed shape EVA specimens, respectively. The material properties are shown in details in Table I.

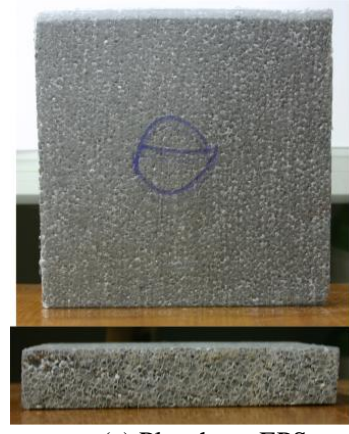

(a) Plat shape EPS

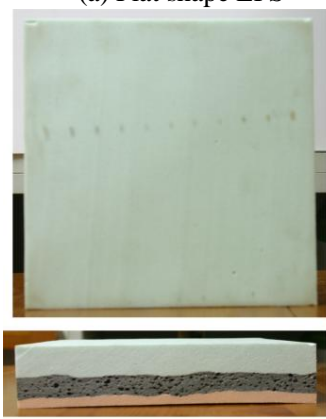

(c) Plat shape EVA

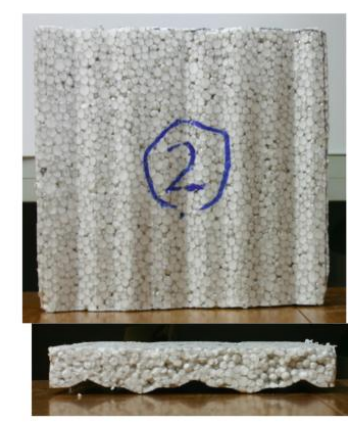

(b) Corrugated shape EPS

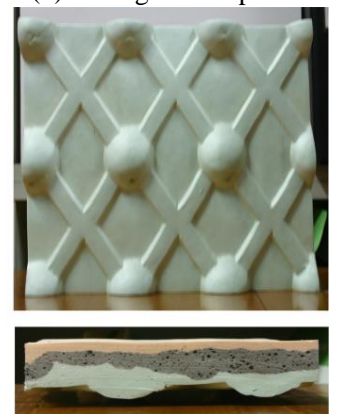

(d) Embossed shape EPS
Fig. 1. Tested resilient materials for reduction of floor impact sound.

TABLE I: PROPERTY OF MATERIALS

\begin{tabular}{llll}
\multicolumn{4}{l}{ TABLE I: PROPERTY OF MATERIALS } \\
\hline \hline Materials & $\begin{array}{l}\text { Thickness } \\
(\mathrm{mm})\end{array}$ & $\begin{array}{l}\text { Density } \\
\left(\mathrm{kgf} / \mathrm{m}^{3}\right)\end{array}$ & Bottom shapes \\
\hline EPS & 30 & 25,13 & Plat, corrugated \\
EVA & 30 & 62 & Plat, embossed \\
\hline \hline
\end{tabular}

\section{SHORT-TERM LOAD TEST}

\section{A. Specimen and Test Method}

A total of 15 specimens were tested to measure the stress vs. strain curves of resilient materials subjected to short-term load. Three parameters were considered in this investigation: types of materials, density, and bottom shapes. The cross sectional dimension of the specimens was $150 \mathrm{~mm}$ square, and the thickness of specimen was $30 \mathrm{~mm}$. Five types of specimens were prepared in the laboratory and three nominally identical specimens were prepared for each specimen type as shown in Table II.

The measurement method and test set-up are shown in Fig. 2. Deflection was measured using four linear variable differential transducers (LVDTs). Four LVDTs were placed vertically at the bottom of the specimen at 90 degrees apart. The short-term load tests were performed using a universal testing machine with $2,000 \mathrm{kN}$ capacity. The load was measured with the electronic load cell of the machine. The readings of the applied load and the corresponding LVDTs were recorded automatically through a data logger at specified load intervals. The test was terminated when the value of strain arrived at about 80 percent.

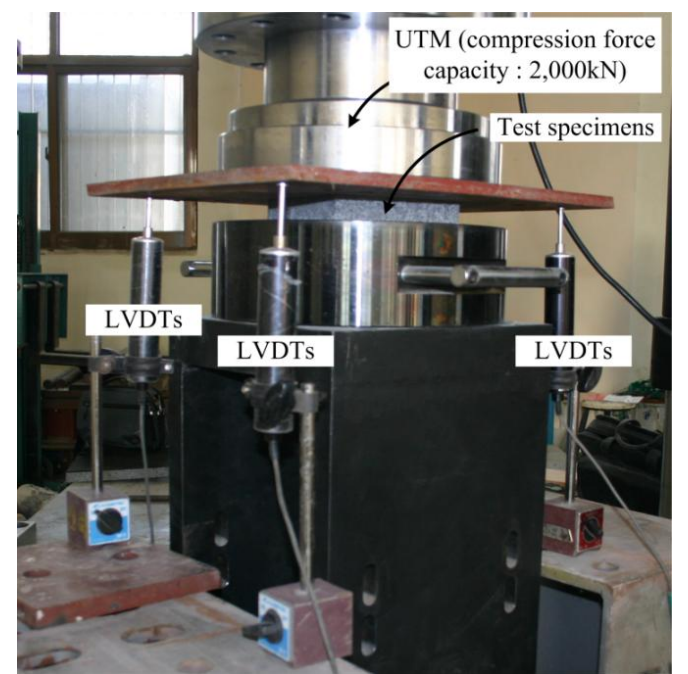

Fig. 2. Test set-up and measurement method for short-term load.

TABLE II: TEST SPECIMENS FOR SHORT TERM LOAD

\begin{tabular}{llll}
\hline \hline Materials & $\begin{array}{l}\text { Thickness } \\
(\mathrm{mm})\end{array}$ & $\begin{array}{l}\text { Density } \\
\left(\mathrm{kgf} / \mathrm{m}^{3}\right)\end{array}$ & Bottom shapes \\
\hline EPS25P-S1 & 30 & 25 & Plat \\
EPS25P-S2 & 30 & 25 & Plat \\
EPS25P-S3 & 30 & 25 & Plat \\
EPS13C-S1 & 30 & 13 & Corrugated \\
EPS13C-S2 & 30 & 13 & Corrugated \\
EPS13C-S3 & 30 & 13 & Corrugated \\
EPS13P-S1 & 30 & 13 & Plat \\
EPS13P-S2 & 30 & 13 & Plat \\
EPS13P-S3 & 30 & 13 & Plat \\
EVA62P-S1 & 30 & 13 & Plat \\
EVA62P-S2 & 30 & 62 & Plat \\
EVA62P-S3 & 30 & 62 & Plat \\
EVA62E-S1 & 30 & 62 & Embossed \\
EVA62E-S2 & 30 & 62 & Embossed \\
EVA62E-S3 & 30 & 62 & Embossed \\
\hline \hline
\end{tabular}

\section{B. Stress vs. Strain Curves of Specimens}

Fig. 3 shows the compressive stress vs. strain curves of tested specimens. The observed structural behavior of the resilient materials subjected to short-term load was similar to that obtained from the compressive tests by Kim et al. [3].

As shown in Fig. 3, the stress vs. strain curves of plat-shape specimens are different to those of the corrugated or embossed-shape specimens. The curves of plat-shape specimens are divided into three stages as follows.

Stage I-the compressive stress of specimen increases with little change in slip.

Stage II-after Stage I, the increasing rate of stress gradually decreases with the increase of strain.

Stage III - the stress of specimen rapidly increases with the increase of strain.

The curves of corrugated or embossed-shape specimens are divided into two stages as follows.

Stage I-at the beginning of loading only the corrugated or embossed sectional area resists against the compressive load. Therefore, the compressive stress of specimen increases with large change in slip. 
Stage II-when the gross sectional area of specimen resists against the compressive load, the stress of specimen rapidly increases with the increase of strain.

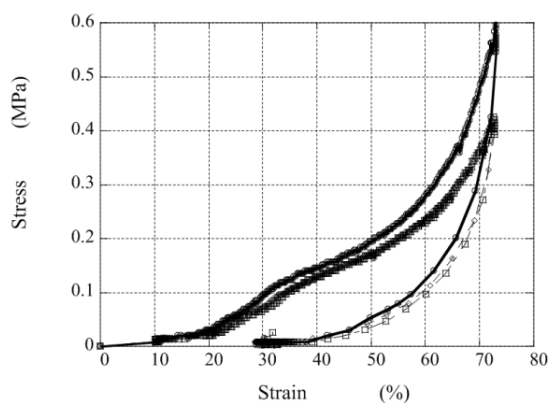

(a) EPS25P-S1,S2,S3

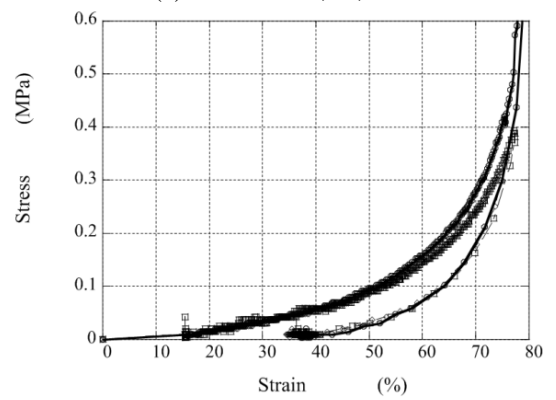

(b) EPS13C-S1,S2,S3

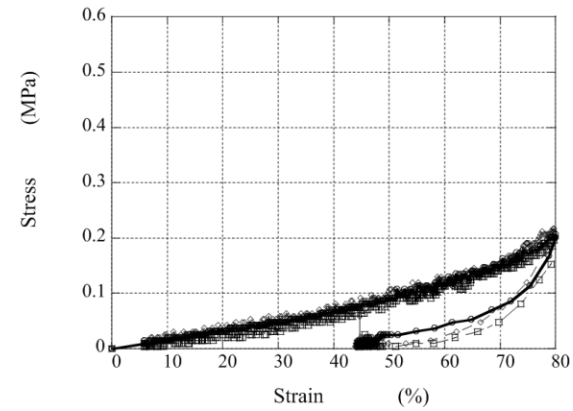

(c) EPS13P- S1,S2,S3

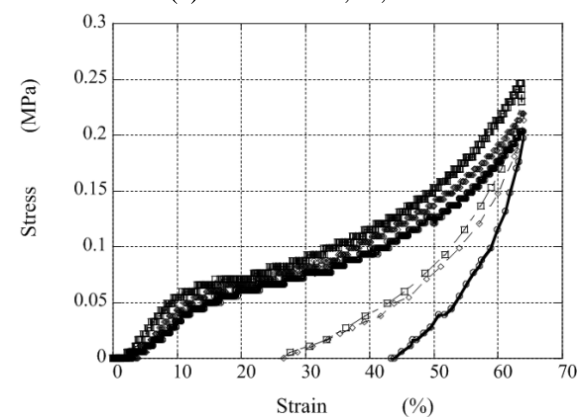

(d) EVA62P-S1,S2,S3

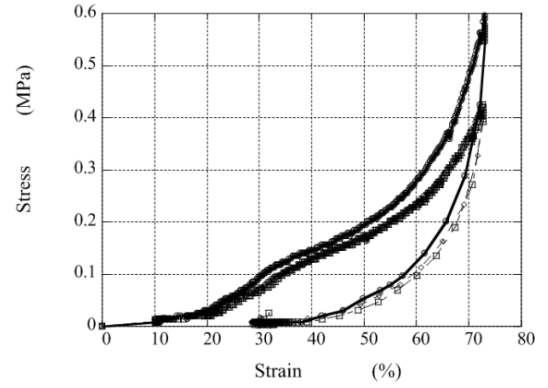

(e) EVA62E- S1,S2,S3

Fig. 3. Compressive stress vs. strain curves of tested specimens.

Test results indicated that the strength of resilient materials was strongly influenced by the types of materials, density, and the bottom shapes of materials. As shown in Table III, when the compressive strain is 0.1, the stresses of EPS25P-S1,
EPS13C-S1, and EPS13P-S1 are 0.081, 0.005, and 0.021MPa, respectively. Similarly, the stresses of EPS62P-S1 and EPS62E-S1 are 0.035 and 0.008 , respectively, at the strain of 0.1 .

\begin{tabular}{llll}
\multicolumn{2}{c}{ TABLE III: STRESS OF TESTED SPECIMENS (UNIT : MPA) } \\
Materials & Strain & Strain & Strain \\
& $(0.1)$ & $(0.2)$ & $(0.3)$ \\
\hline EPS25P-S1 & 0.081 & 0.121 & 0.141 \\
EPS25P-S2 & 0.110 & 0.160 & 0.181 \\
EPS25P-S3 & 0.121 & 0.150 & 0.181 \\
EPS13C-S1 & 0.005 & 0.017 & 0.032 \\
EPS13C-S2 & 0.004 & 0.016 & 0.031 \\
EPS13C-S3 & 0.005 & 0.017 & 0.032 \\
EPS13P-S1 & 0.021 & 0.037 & 0.051 \\
EPS13P-S2 & 0.019 & 0.034 & 0.045 \\
EPS13P-S3 & 0.018 & 0.022 & 0.038 \\
EVA62P-S1 & 0.035 & 0.061 & 0.073 \\
EVA62P-S2 & 0.044 & 0.067 & 0.083 \\
EVA62P-S3 & 0.054 & 0.071 & 0.084 \\
EVA62E-S1 & 0.008 & 0.033 & 0.093 \\
EVA62E-S2 & 0.009 & 0.027 & 0.075 \\
EVA62E-S3 & 0.010 & 0.020 & 0.073
\end{tabular}

\section{LONG-TERM LOAD TEST}

\section{A. Specimen and Test Method}

TABLE IV: TEST SPECIMENS

\begin{tabular}{lllll}
\hline \hline Materials & $\begin{array}{c}\text { Load } \\
(\mathrm{mm})\end{array}$ & $\begin{array}{l}\text { Density } \\
\left(\mathrm{kgf} / \mathrm{m}^{3}\right)\end{array}$ & $\begin{array}{l}\text { Loading } \\
\text { Period (days) }\end{array}$ & $\begin{array}{l}\text { Bottom } \\
\text { shapes }\end{array}$ \\
\hline EPS25P-L1 & 230 & 25 & 45 & Plat \\
EPS25P-L2 & 1,250 & 25 & 45 & Plat \\
EPS25P-L3 & 2,500 & 25 & 7 & Plat \\
EPS13C-L1 & 230 & 13 & 45 & Corrugated \\
EPS13C-L2 & 1,250 & 13 & 45 & Corrugated \\
EPS13C-L3 & 2,500 & 13 & 7 & Corrugated \\
EVA62E-L1 & 230 & 13 & 45 & Embossed \\
EVA62E-L2 & 1,250 & 62 & 45 & Embossed \\
EVA62E-L3 & 2,500 & 62 & 7 & Embossed \\
\hline \hline
\end{tabular}

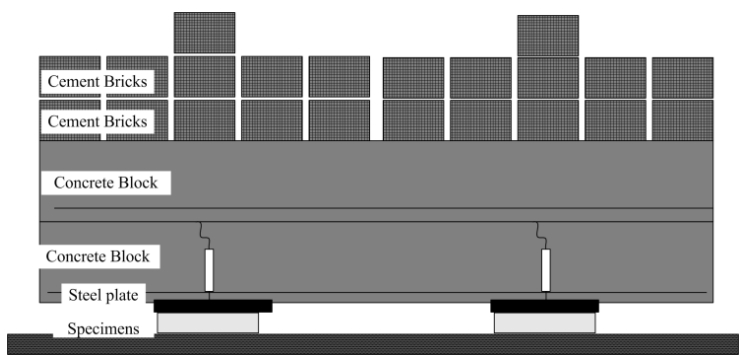

Fig. 4. Test set-up for the specimens subjected to long-term load.

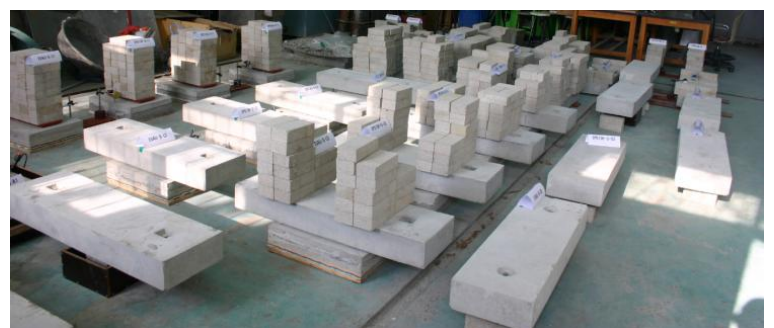

Fig. 5. Photo for the specimens subjected to long-term load.

A total of 9 specimens were tested to measure the deflection of materials subjected to long-term load. Three parameters were considered in this investigation: types of materials, density, and bottom shapes. The cross sectional 
dimension of the specimens was $150 \mathrm{~mm}$ square, and the thickness of specimens was $30 \mathrm{~mm}$. Three types of specimens were prepared in the laboratory as shown in Table IV. The measurement method and test set-up are shown in Fig. 4. The long-term load tests were performed by putting concrete blocks and cement bricks on the top of specimens. The weigh of a concrete block and a cement brick was $860 \mathrm{~N}$ and $18.5 \mathrm{~N}$, respectively. Three types of loads were applied to the specimens: $230 \mathrm{~N}, 1,250 \mathrm{~N}$, and $2,500 \mathrm{~N}$. The $230 \mathrm{~N}$ and $1,250 \mathrm{~N}$ were loaded on the specimens during 45 days, whereas the $2,500 \mathrm{~N}$ was loaded during 7 days. The deflection of specimen was measured using a digital dial gage which was placed vertically on the top of the specimen. Fig. 5 shows the specimens subjected to long-term load.

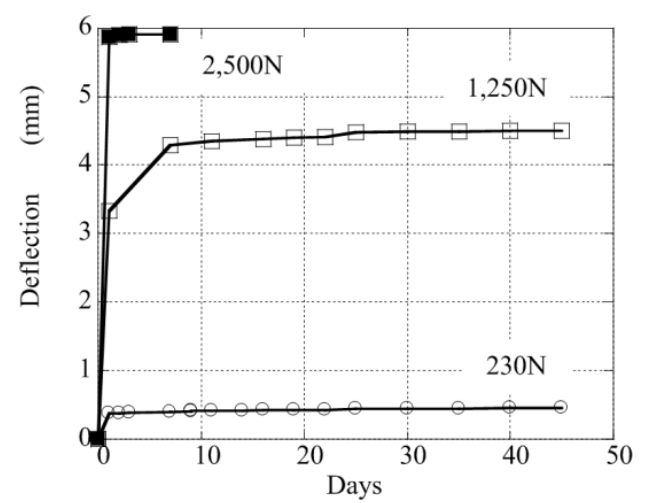

(a) EPS25P-L1,L2,L3

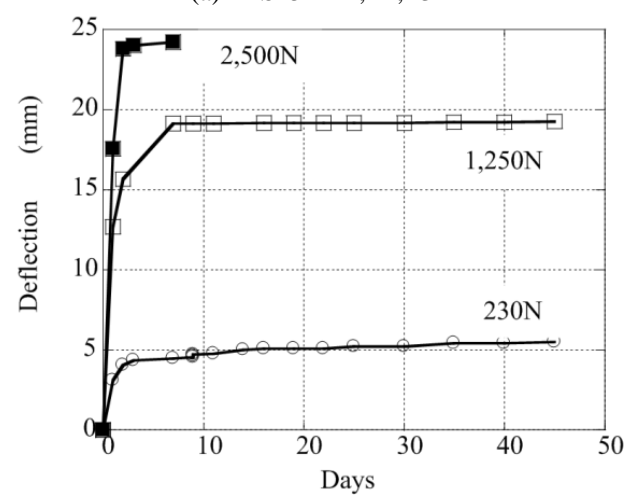

(b) EPS13C-L1,L2,L3

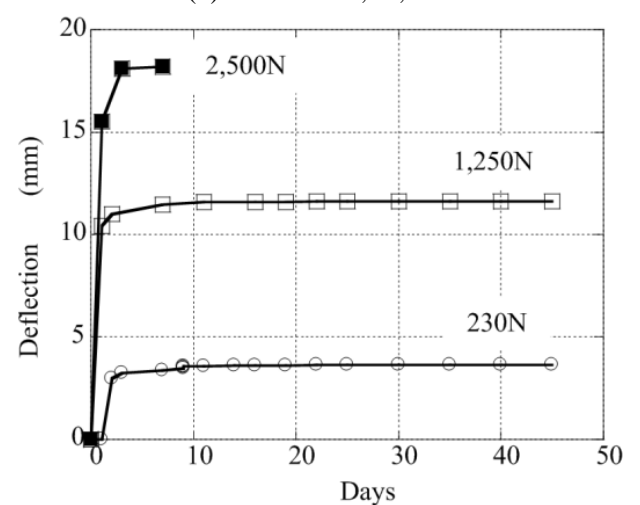

(c) EVA62E- L1,L2,L3

Fig. 6. Deflections of tested specimens subjected to long-term load.

\section{B. Deflections}

Fig. 6 shows the deflections of tested specimens subjected to long-term load. The deflection of tested specimens increased with the increase of load. In addition, when the resilient materials are subjected to long-term load, the deflection gradually increased with loading period. Specially, the deflection of tested specimens rapidly increased during the first two or three days. After the first rapid increase of deflection, the deflection of tested specimens little increased with time.

\section{COMPARISONS}

Fig. 7 compares the strain of specimens subjected to short-term load and that subjected to long-term load. As shown in Fig. 7, the deflection of specimens subjected to long-term load is much greater than that of the specimens subjected to short-term load. When the stress is about $0.012 \mathrm{MPa}$, the difference between the strain under short-term load and the strain under long-term load is little, whereas when the stress is about $0.05 \mathrm{MPa}$, the strain under long-term load is about $150 \%$ greater than that of the strain under short-term load.

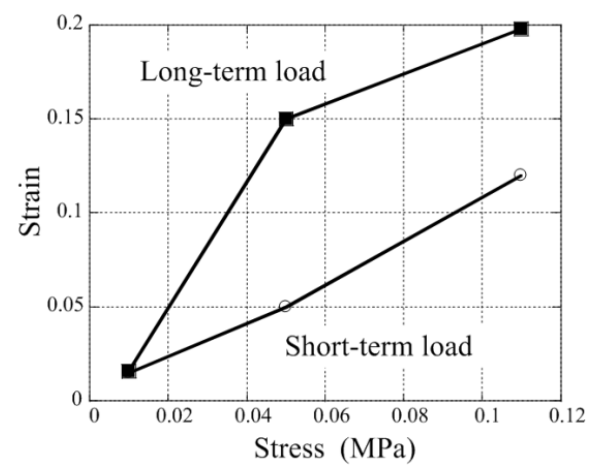

(a) EPS25P

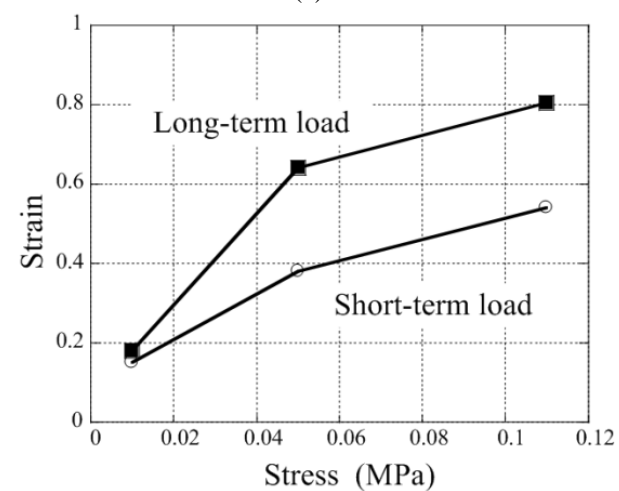

(b) EPS13C

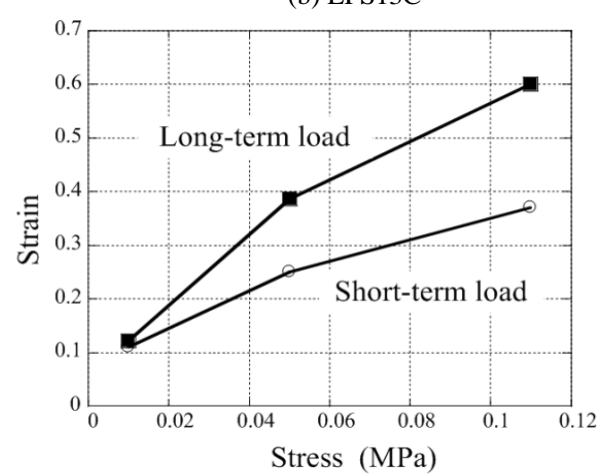

(c) EVA62E

Fig. 7. Comparisons between the strain of specimens subjected to short-term load and that subjected to long-term load.

\section{CONCLUSION}

1) Stress and strain curves of resilient materials for reduction of floor impact sound were strongly influenced 
by types of materials, density, and bottom shapes. The curves of plat-shape specimens were divided into three stages, whereas the curves of plat-shape specimens were divided into three stages.

2) The deflection of specimens subjected to long-term load was much greater than that of the specimens subjected to short-term load. When the stress is about $0.05 \mathrm{MPa}$, the strain under long-term load is approximately $150 \%$ greater than that of the strain under short-term load.

3) As the deflection of resilient materials for reduction of floor impact sound increased with loading time, the influence of long-term load should be included in order to determine the structural characteristics of resilient materials for reducing floor impact sound

\section{ACKNOWLEDGMENT}

This research was supported by a grant (13CTAP-C066421-01) from Construction \& Transportation Technology Advancement Research Program funded by Ministry of Land, Transport and Maritime Affairs of Korean government.

\section{REFERENCES}

[1] K.-W. Kim, K.-S. Yang, J.-Y. Chung, J.-B. Im, and G.-C. J., "A study on the heavy-weight floor impact sound reduction evaluation of characteristics by resilient materials," in Proc. of the KSNVE Annual Conf., Seoul, 2007, CD printing.

[2] J.-B. Im, J.-Y. Chung, K.-W. Kim, and G.-C. Jeong, "A study on dynamic stiffness of multi-layered damping materials," in Proc. of the KSNVE Annual Conf. Seoul, 2007, CD printing.

[3] K.-W. Kim, G.-C. Jeong, K.-S. Yang, and J.-Y. S, "Correlation between dynamic stiffness of resilient materials and heavyweight impact sound reduction level," Building and Environment, vol. 44, pp. 1589-1600, 2009.

[4] DIN EN 12431, Thermal Insulating Products for Building Applications-Determination of Thickness for Floating Floor Insulating Products, 2007.

[5] ISO 20392, Thermal-insulation Materials-Determination of Compressive Creep, International Standard, 2007.

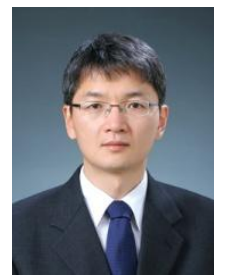

Jung-Yoon Lee is a professor in the Department of Civil and Architectural Engineering at Sungkyunkwan University, Republic of Korea. He is involved in the committees, Shear and Torsion and Seismic Design of the Korean Concrete Institute Committee. He has performed extensive research on the shear behavior and seismic design of reinforced and prestressed concrete buildings.

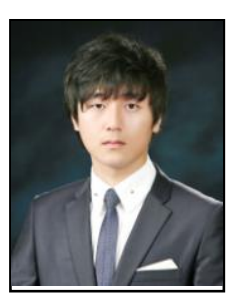

Seong-Ho Choi is a graduate of Architectural Engineering at Sungkyunkwan University, Republic of Korea. He is a member of Korean Concrete Institute. His major study is shear behavior of reinforced concrete beams.

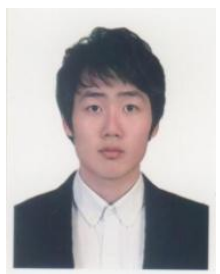

Su-Chan Lee is a graduate of Architectural Engineering at Sungkyunkwan University, Republic of Korea. He is a member of Korean Concrete Institute. His major study is torsional behavior of reinforced concrete beams.

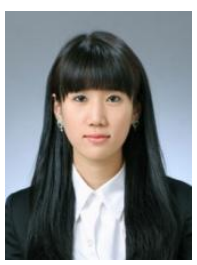

A-Ra Lim is a graduate of Architectural Engineering at Sungkyunkwan University, Republic of Korea. She is a member of Korean Concrete Institute. Her major study is FRP concrete.

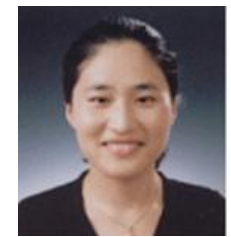

Ji-Sun Park is a research specialist of Advanced Building Research Division, Building Research Department, Korea Institute of Construction Technology, Republic of Korea. She is a member of Korean Concrete Institute. Her major study is FRP concrete.

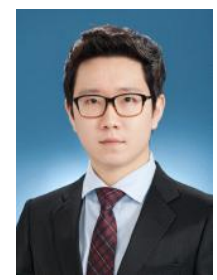

Jong-Mun Kim is a graduate of Architectural Engineering at Sungkyunkwan University, Republic of Korea. He is a member of Korean Concrete Institute. His major study is insulation and interlayer noise. 